\title{
Review
}

Fetal Diagnosis

ant Therapy

\section{Assessment of Fetal Myocardial Deformation Using Speckle Tracking Techniques}

\author{
Ioannis Germanakis ${ }^{a}$ Helena Gardiner ${ }^{b, c}$ \\ ${ }^{a}$ Faculty of Medicine, University of Crete, Heraklion, Greece; ${ }^{b}$ Division of Cancer, Faculty of Medicine, Imperial \\ College London, and 'Queen Charlotte's and Chelsea and the Royal Brompton NHS Foundation Trust Hospitals, \\ London, UK
}

\section{Key Words}

Fetal heart $\cdot$ Speckle tracking $\cdot$ Myocardial strain

\begin{abstract}
Objective: To report the current status of speckle tracking techniques in evaluation of fetal myocardial deformation. Methods: A variety of non-Doppler ultrasound methods are available using offline analysis of standard four-chamber and short axis views of the heart. Results: Most reports have used techniques developed for the measurement of strain and strain rate in the adult heart and produced conflicting descriptions of gestational changes in strain. Myocardial velocities usually reflect mean modal velocities and are lower than the peak velocities obtained using Doppler techniques. Conclusions: In the fetus, most current methods of acquisition result in frame rates that are too low, and the fetal heart size is too small to achieve reliable measures of fetal myocardial deformation.

Copyright ๑ 2012 S. Karger AG, Basel
\end{abstract}

\section{Introduction}

A variety of investigative techniques have been used to assess fetal myocardial function; myocardial velocities [1-3] and strain and strain rate [4] have been measured using tissue Doppler, while the use of color tissue Doppler has been evaluated in the fetus $[5,6]$. Recent reports describe the use of non-Doppler technology, i.e. $2 \mathrm{D}$ speckle tracking, in the measurement of myocardial deformation indices [7-16]. How could this latest modality be useful in understanding fetal heart function? Evaluation of fetal myocardial performance using 2D speckle tracking requires no additional imaging, in contrast to Doppler-based techniques, and uses routinely acquired 2D images which are suitable for post-processing and offline analysis [17]. This angle-independent method can measure strain and strain rate and has the potential to record complex fetal myocardial function such as torsion or twist. Provided their acquisition is readily available in clinical practice and accurately reflects fetal physiology and pathophysiology, it may provide new insights into fetal myocardial function in health and disease states.

\section{KARGER}

Fax +4161306 1234

E-Mail karger@karger.ch

www.karger.com
(C) 2012 S. Karger AG, Basel

$1015-3837 / 12 / 0322-0039 \$ 38.00 / 0$

Accessible online at:

www.karger.com/fdt
Helena M. Gardiner, PhD, MD, FRCP, FRCPCH, DCH

Institute of Reproductive and Developmental Biology

Faculty of Medicine, Imperial College, Queen Charlotte's and Chelsea Hospital

Du Cane Road, London, W12 0HS (UK)

Tel. +44207351 8719, E-Mail helena.gardiner@imperial.ac.uk 


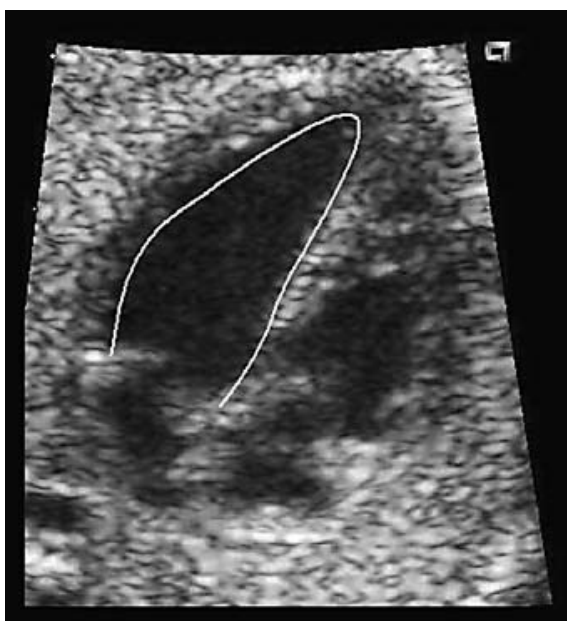

Fig. 1. Optimal orientation of the fetal heart with the apex uppermost and the septum tilted slightly laterally to ensure that the true apex is included and to enable feature recognition of the AV valve.

\section{Strain and Strain Rate}

Strain is a measure of tissue deformation in response to an applied force [18] and may be described as a percentage of the original dimension with the speed of deformation as strain rate [19-21]. A one-dimensional object (a line) can either increase or decrease its length when a force is applied. Strain $(\varepsilon)=\mathrm{L}-\mathrm{L}_{\mathrm{o}} / \mathrm{L}_{\mathrm{o}}$, where $\mathrm{L}$ and $\mathrm{L}_{\mathrm{o}}$ correspond to the final and initial lengths, respectively. Negative strain values describe shortening (usually in systole), and positive ones describe lengthening (usually in diastole) relative to the initial dimension. Instantaneous strain refers to the instantaneous observed deformation $\mathrm{L}(\mathrm{t})$ relative either to the initial length $\left(\mathrm{t}_{\mathrm{o}}\right)$ (Lagrangian strain) or to a previous length observed at an infinitesimal time interval during the deformation process (natural strain); the sum of all instantaneous strains comprises the total strain [12] (fig. 3). To measure myocardial deformation, both the initial and the final dimensions of the cardiac segment or free wall, as well as the time interval during which this deformation takes place, must be accurately measured. The difference in the distance of tracked myocardium between the initial and final frames (or between subsequent frames) corresponds to the degree of deformation or strain of the myocardial segment. The strain rate is derived from this by dividing the strain by the time interval between the corresponding frames. However, heart deformation is complex and encompasses longitudinal, radial, and circumferential strain [22, 23].

\section{Principles of Speckle Tracking}

Two imaging approaches have been used to measure myocardial deformation. The original echocardiographic technique was based on the estimation of instantaneous myocardial velocity differences or gradients along a myocardial segment, similar to Doppler. Using this approach, the strain rate is measured first and the strain is derived from the time integral $[19,21,23,24]$. However, although the temporal resolution of Doppler-based echocardiographic techniques is excellent, angle dependency limits their utility (particularly in the fetus). Thus, the second approach uses $2 \mathrm{D}$ tracking techniques similar to myocardial tagging in MRI [25]. These non-Doppler optical methods use speckle tracking and are referred to variably as: multi-scale motion mapping, automatic functional imaging, or velocity vector imaging (VVI) [23]. They permit quantification of myocardial deformation using frame-by-frame tracking of bright myocardial areas - temporarily stable acoustic markers (kernels) resulting from constructive and deconstructive interfaces of ultrasound beams created from structures shorter than their wavelengths [23]. These natural acoustic markers can be identified in two-dimensional echocardiographic images and tracked from frame to frame to provide velocity and displacement data. Speckle tracking has the potential to use easily acquired digital data from routine echocardiograms and store the vectors and absolute velocities in a spreadsheet to allow assessment of complex heart motion (fig. 1). It can assess alterations in rigid myocardial motion (such as translation and rotation) and deformation indices: myocardial thickening and thinning, shear stress cardiac torsion [26-28] including apical twisting (incorporating axial shortening) [29], radial motion, and local thickening. Because it allows beat-to-beat analysis, it may enable functional analysis during periods of arrhythmia [30, 31].

\section{Validation of Different Speckle Tracking Techniques}

Different tracking algorithms are used by various ultrasound systems, sometimes combining speckle tracking techniques with pattern (or feature) recognition algorithms based on common forms of adult left ventricular shape and motion. A list of speckle tracking software and providers is presented in table 1, and preliminary reports comparing the performance of different commercial speckle tracking software in adults have shown similar performance [32]. Echocardiographic (2D) 
Fig. 2. Fetal ECG gating may be achieved using a dummy signal to permit export of the original DICOM frame rate to the software for offline analysis.
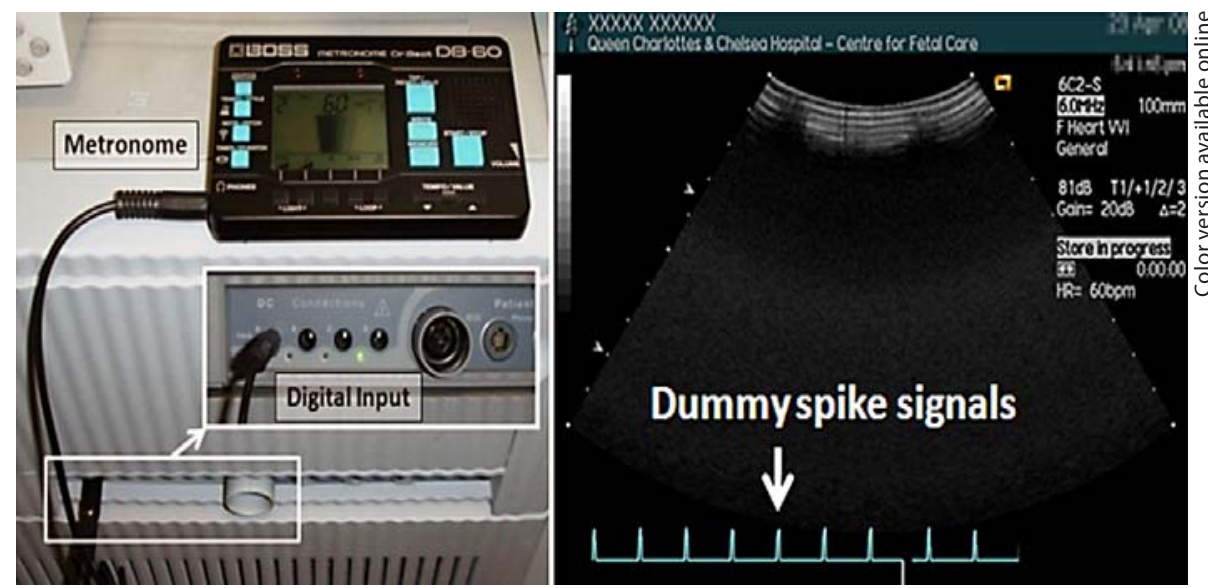

Table 1. Web links to commercially available echocardiography speckle tracking software

\begin{tabular}{ll}
\hline Siemens syngo Velocity Vector Imaging & $\begin{array}{l}\text { http://www.medical.siemens.com/siemens/ko_KR/gg_us_FBAs/files/misc_downloads/ } \\
\text { Whitepaper_Jackson.pdf }\end{array}$ \\
\hline GE 2D Strain & $\begin{array}{l}\text { http://www.vivid7ultrasound.com/pdf/vivid7ultrasound.com/Vivid_7_2D_Strain_ } \\
\text { Brochure.pdf }\end{array}$ \\
\hline $\begin{array}{ll}\text { Philips QLAB-Cardiac Motion/Mechanics } \\
\text { Quantification and 3DQ Advanced }\end{array}$ & $\begin{array}{l}\text { http://www.healthcare.philips.com/in_en/products/ultrasound/technologies/QLAB/ } \\
\text { cardiac/cardiac_3DQA_qlab.wpd }\end{array}$ \\
\hline Aloka 2D Tissue Tracking (2D TT) & http://www.aloka-europe.com/entity288.aspx \\
\hline Toshiba 2D3D Wall Motion Tracking & http://www.medical.toshiba.com/downloads/WP-3DWMT-Gorissen-Online.pdf \\
\hline
\end{tabular}

speckle tracking techniques have been validated using sonomicrometry $[23,33]$ in phantoms $[20,23,29,34]$ and animal models $[33,35,36]$ and against MRI $[27,33,37$, 38 ] and tissue Doppler strain measurements in adult subjects [38].

\section{Practical Guidelines in Performing Speckle Tracking}

Most speckle tracking techniques are semi-automated, but the user is responsible for drawing the tracking line defining the endocardial border of the ventricle from the four-chamber or short axis view, placing it along the endocardial border, apex, and atrioventricular valve (AV) annulus in a single frame of a stored heart cycle. The software then automatically tracks the border between the cavity and the endocardium in subsequent frames. The user can adjust the tracking line or reject inappropriately tracked segments from further analysis. As fetal clips are not ECG gated, an alternative method must be used to al- low appropriate timing and to ensure that all frames can be used by the software (fig. 2). One such method is 'acoustic capture'. It can be used in the fetus where there is no ECG to transfer high frame rates. This is available on Siemens machines and is performed from cine review, not during real-time imaging. In the absence of an ECG, the cardiac cycle is determined from mechanical movements, usually the mitral valve movement or anatomic M-mode - the latter concomitantly superimposed on the 2D image to detect systole and diastole [14, 15]. Depending on the sonographic view selected, the software divides the tracking line into corresponding myocardial segments and provides either global (average values for the whole tracking line) or segmental strain. Common measurable parameters include displacement, strain, and strain rate (fig. 3, 4a). Depending on the software used, additional parameters can be measured, including a graphic display of myocardial velocity vectors and their projections on a user-defined virtual axis (usually aligned along the ventricular septum in four-chamber views) or 


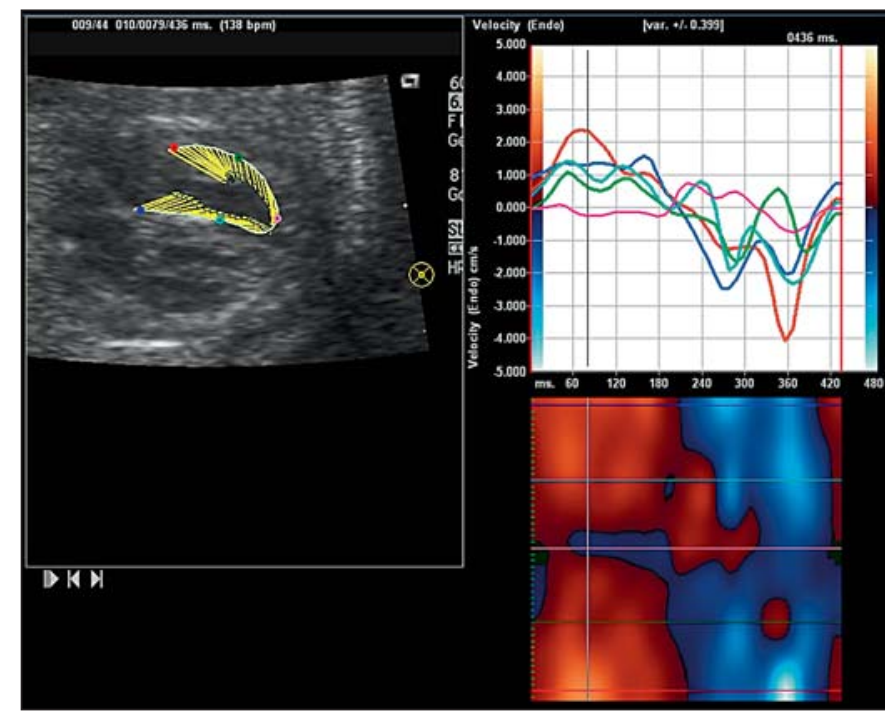

Fig. 3. The displacement of the lateral and septal basal, mid-ventricular, and apical points of the left ventricular endocardial tracking line, relative to a user-defined reference point (yellow target placed on the heart apex) (left), allows VVI software to generate and graphically display the velocity (y-axis)-time ( $\mathrm{x}$-axis) profile for each point (right). Only high frame rate image acquisition permits the detection of both early and late diastolic velocity components (e and a waves, the two negative peaks of the velocity curves).

an estimation of radial strain displayed on a bull's-eye view, color-coded, 17-segment diagram showing graphic and numeric displays of segment asynchrony.

\section{Controversies and Potential Limitations of Speckle Tracking in the Fetus}

Important challenges in making an accurate functional assessment of the fetal heart include its small size, high heart rate, variable orientation of the fetus relative to the ultrasound beam, fetal motion, the distance of the ultrasound probe from the fetal heart, and, at times, increased ultrasound absorption due to maternal adiposity. Thus, although much has been written about the positive contribution that the angle independency of newer techniques may make, it cannot compensate for all of the potential difficulties associated with scanning the fetal heart. Fetal myocardial strain has been measured invasively in animal models [36], but no comparable studies are available in the human. Reports using speckle tracking confirm the previous Doppler-based observations that myocardial velocities increase with gestation, but controversy remains regarding gestational changes in myocardial strain. Some report a gestational decrease in strain in both ventricles [12], others only in the right ventricle $[7,16]$, and others report no change in strain at all $[4,8,9,11]$. Whether these differences represent differences in study design and power or reflect the inconstant performance of different speckle tracking algorithms in the fetus remains to be decided.

Successful application of speckle tracking techniques developed for use in the adult heart requires careful consideration in the fetus. As all speckle tracking techniques are based on offline analysis of cine loops, the performance of the method largely reflects the quality of the available images. Studies report on average an $85 \%$ success rate in unselected populations of pregnant women $[8$, $9,12,14]$, rising to $98 \%$ if image quality case selection such as a low maternal BMI is applied [16]. Table 2 lists the characteristics and contribution to the literature of the fetal studies published in the English language to date.

Listed are some potential pitfalls:

(1) Optimal imaging: storing specific presets is recommended to obtain optimal contrast between the ventricular cavity and endocardium, using harmonic imaging when necessary and minimizing endocardial border dropout and ensuring good contrast in the area of AV insertion (particularly when feature recognition software is used). Scanning planes should avoid acoustic shadowing over the fetal heart, and a slightly angled four-chamber view provides optimal contrast [16]. Scanning perpendicular to the ventricular septum can result in poor VVI tracking of AV and underestimation of both basal and global deformation measurements [14].

(2) Chamber foreshortening: we recommended using the routine four-chamber view from a transverse cut of the fetal thorax. Serial studies of speckle tracking are best performed using the same acquisition plane, as a four-chamber view obtained in a superior or inferior plane, or with lateral angulation, may result in a false appreciation of ventricular size. If the cardiac apex is omitted in foreshortened images, increased mobility of the false apex against the heart base results in overestimation of strain.

(3) Maternal-fetal movements: almost all speckle tracking algorithms use some form of pattern recognition that anticipates the heart will return to its initial position following a complete cardiac cycle. If this is not the case, due to fetal movement or maternal respiration, tracking will be inaccurate. Several video loops (on- 


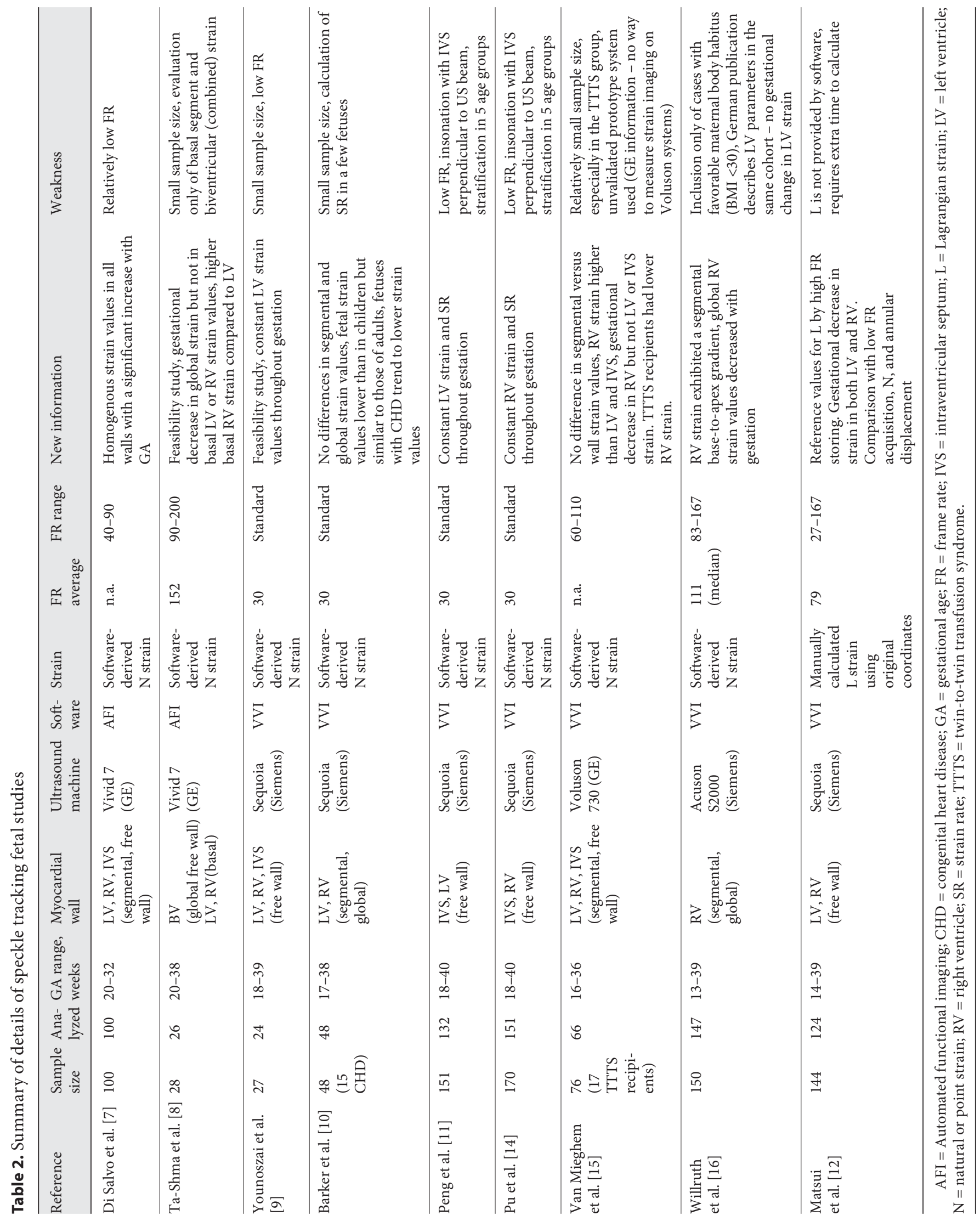




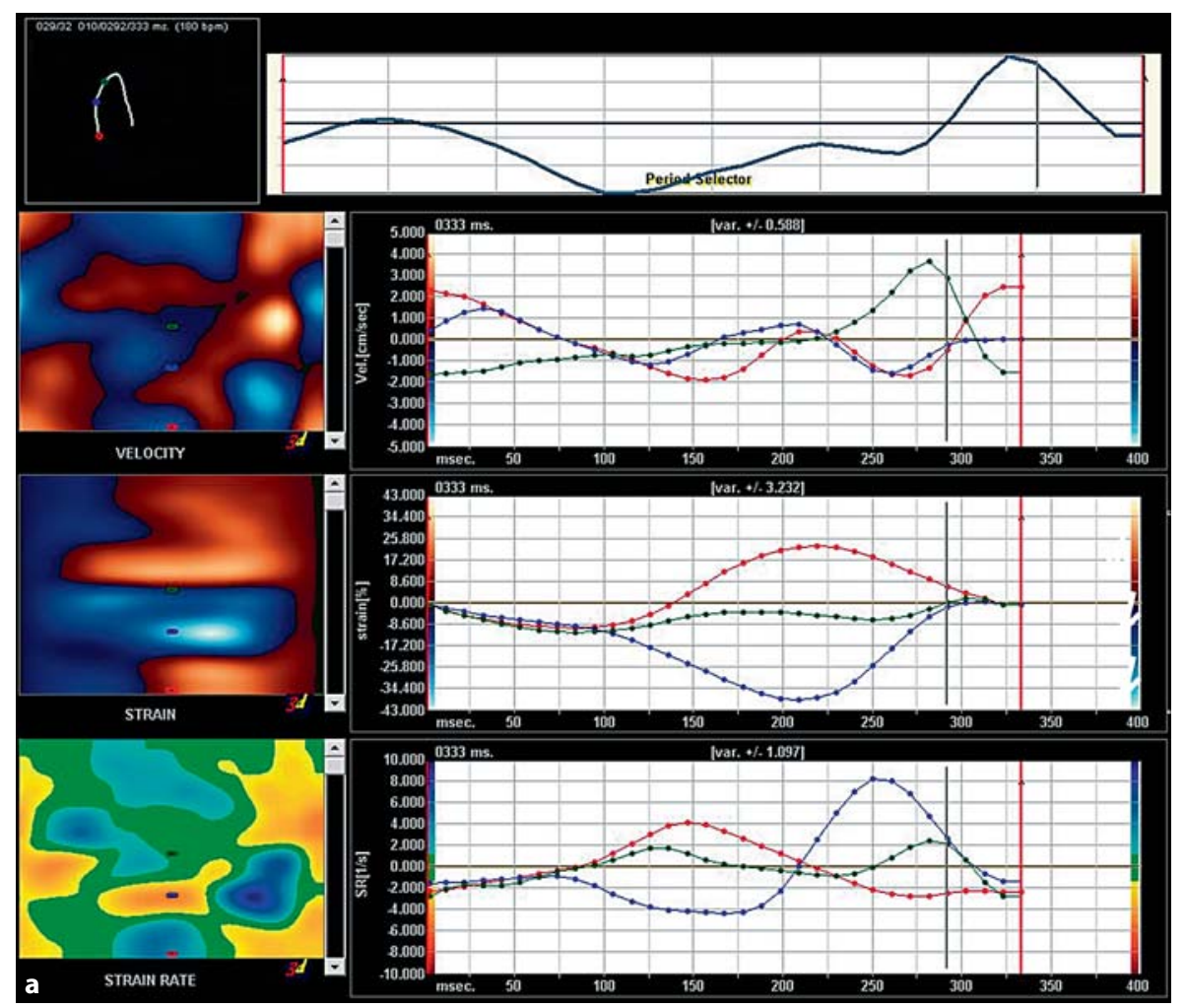

Fig. 4. a Software calculates natural strain by placing points at very short distances along the free walls of the fetal heart and calculating point strain. b Point strain shows marked segmental variation and the values are summed to provide an average point, or natural strain.

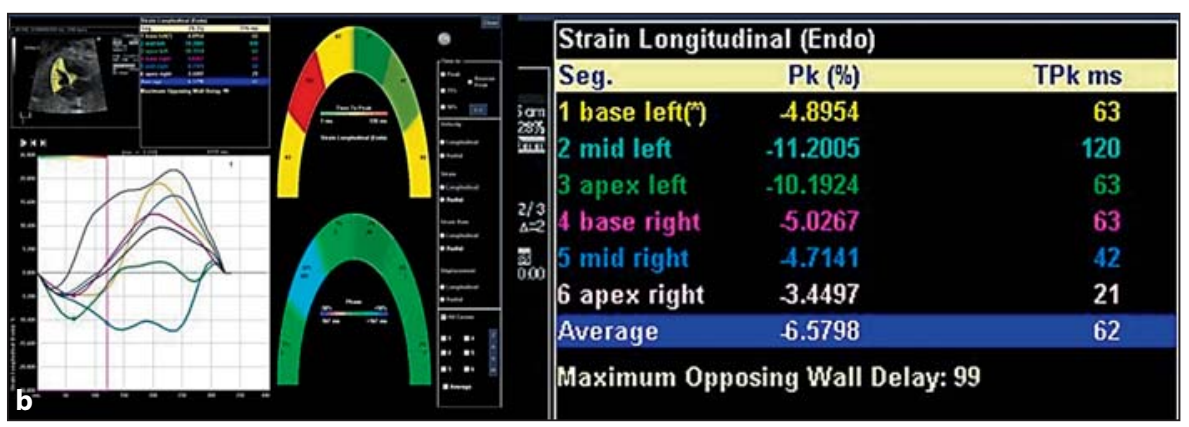

line suppl. videos 1-4; for all online suppl. material, see www.karger.com/doi/10.1159/000330378) recorded during maternal breath holding are recommended to optimize the recordings.

(4) Frame rate: imaging at the highest possible frame rate is essential as low frame rates can result in tracking failure and, most importantly, underestimation of time-dependent variables such as velocities and strain rate. At least 60-110 frames per second are recommended when imaging the adult heart $[13,39,40]$, and even higher rates are desirable to provide enough frames per heart beat in the fetus [12]. The frame rate is optimized by using the narrowest possible ultrasound field and avoiding multiple focal zones during image acquisition. However, failure to realize that the analysis may not be performed at the original high frame rate is an important pitfall. In the absence of fetal ECG gating, some ultrasound machines only allow data transfer at standard video rates of 25-30 frames per second (online suppl. videos 1-4) (depending on the country). This is unacceptably low for speckle tracking analysis, as it corresponds to only 10 frames per fetal cardiac cycle on average [12]. To interpret their data appropriately, it is important that users know the frame rate available for speckle tracking analysis of their stored images. Use of a dummy ECG signal permits transfer of images at the original DICOM rate (fig. 2). Manufacturers have developed 
modifications such as acoustic capture to enable capture of all frame rates for analysis [16].

(5) Optimal offline image analysis: although speckle tracking techniques are computer based, they are not user independent. The user must place or modify the tracking lines. A reasonable learning curve is essential before introducing the technique into clinical or research studies, and intra- and interobserver variability should always be reported.

(6) Should strain be reported from software derived values or from original coordinates? Speckle tracking software produces a wide range of segmental and global parameters displayed in graphic form that have been reported in many studies, sometimes without due consideration of the underlying technical constraints of the method in the fetal heart $[9-11,14-16]$. VVI software provides strain and strain values based on instantaneous velocity gradients of adjacent myocardial segments (natural strain). However, the major limitation of this automated method is spatial resolution; it is recommended that measurements of strain not be made if adjacent segments are less than 2-5 mm apart [19], which is usually the case with points placed automatically by the software in the fetal heart (fig. $4 \mathrm{~b}$ ). However, several systems store the original tracking coordinates that can be used to manually estimate the entire free wall or Lagrangian strain which may more accurately reflect function in the small fetal heart [12]. Some studies report global rather than segmental values which may be more representative of heart function in the fetus for two reasons: firstly, segmental dysfunction is less likely compared to the adult with coronary artery disease, and secondly strain measured in longer myocardial distances is more likely to reflect true values than point (natural) strain in studies reporting segmental values.

\section{Conclusions}

The feasibility of myocardial speckle tracking has already been proven in the fetus. It offers the unique potential of performing complex measurements of myocardial function offline, based on routinely obtained echocardiographic images, and could be developed as a useful clinical tool to study the impact of congenital heart disease on fetal myocardial function. However, it is important to understand the basic principles of strain and the resulting limitations of each approach before adopting it into routine clinical practice.

\section{References}

- 1 Harada K, Tsuda A, Orino T, Tanaka T, Takada G: Tissue Doppler imaging in the normal fetus. Int J Cardiol 1999;71:227-234.

-2 Tutschek B, Zimmermann T, Buck T, Bender HG: Fetal tissue Doppler echocardiography: detection rates of cardiac structures and quantitative assessment of the fetal heart. Ultrasound Obstet Gynecol 2003;21:26-32.

>3 Gardiner HM, Pasquini L, Wolfenden J, Barlow A, Li W, Kulinskaya E, Henein M: Myocardial tissue Doppler and long axis function in the fetal heart. Int J Cardiol 2006;113:3947.

4 Perles Z, Nir A, Gavri S, Rein AJ: Assessment of fetal myocardial performance using myocardial deformation analysis. Am J Cardiol 2007;99:993-996.

5 Di Salvo G, Russo MG, Paladini D, Pacileo G, Felicetti M, Ricci C, Cardaropoli D, Palma M, Caso P, Calabro R: Quantification of regional left and right ventricular longitudinal function in 75 normal fetuses using ultrasound-based strain rate and strain imaging. Ultrasound Med Biol 2005;31:1159-1162.

-6 Larsen LU, Petersen OB, Norrild K, Sorensen K, Uldbjerg N, Sloth E: Strain rate derived from color Doppler myocardial imaging for assessment of fetal cardiac function. Ultrasound Obstet Gynecol 2006;27:210-213.

$>7$ Di Salvo G, Russo MG, Paladini D, Felicetti M, Castaldi B, Tartaglione A, di Pietto L, Ricci C, Morelli C, Pacileo G, Calabro R: Two-dimensional strain to assess regional left and right ventricular longitudinal function in 100 normal foetuses. Eur J Echocardiogr 2008;9:754-756.

$>8$ Ta-Shma A, Perles Z, Gavri S, Golender J, Tarshansky S, Shlichter C, Bar Tov H, Rein AJ: Analysis of segmental and global function of the fetal heart using novel automatic functional imaging. J Am Soc Echocardiogr 2008;21:146-150.

$>9$ Younoszai AK, Saudek DE, Emery SP, Thomas JD: Evaluation of myocardial mechanics in the fetus by velocity vector imaging. J Am Soc Echocardiogr 2008;21:470-474.

10 Barker PC, Houle H, Li JS, Miller S, Herlong JR, Camitta MG: Global longitudinal cardiac strain and strain rate for assessment of fetal cardiac function: novel experience with velocity vector imaging. Echocardiography 2009;26:28-36.

11 Peng QH, Zhou QC, Zeng S, Tian LQ, Zhang M, Tan Y, Pu DR: Evaluation of regional left ventricular longitudinal function in 151 normal fetuses using velocity vector imaging. Prenat Diagn 2009;29:1149-1155.

12 Matsui H, Germanakis I, Kulinskaya E, Gardiner HM: Temporal and spatial performance of vector velocity imaging in the human fetal heart. Ultrasound Obstet Gynecol 2011;37:150-157.

13 Mondillo S, Galderisi M, Mele D, Cameli M, Lomoriello VS, Zaca V, Ballo P, D’Andrea A, Muraru D, Losi M, Agricola E, D’Errico A, Buralli S, Sciomer S, Nistri S, Badano L: Speckle-tracking echocardiography: a new technique for assessing myocardial function. J Ultrasound Med 2011;30:71-83.

14 Pu DR, Zhou QC, Zhang M, Peng QH, Zeng S, Xu GQ: Assessment of regional right ventricular longitudinal functions in fetus using velocity vector imaging technology. Prenat Diagn 2010;30:1057-1063.

15 Van Mieghem T, Giusca S, DeKoninck P, Gucciardo L, Done E, Hindryckx A, D'Hooge J, Deprest J: Prospective assessment of fetal cardiac function with speckle tracking in healthy fetuses and recipient fetuses of twinto-twin transfusion syndrome. J Am Soc Echocardiogr 2010;23:301-308. 
$\checkmark 16$ Willruth AM, Geipel AK, Fimmers R, Gembruch UG: Assessment of right ventricular global and regional longitudinal peak systolic strain, strain rate and velocity in healthy fetuses and impact of gestational age using a novel speckle/feature-tracking based algorithm. Ultrasound Obstet Gynecol 2011;37: 143-149.

$\checkmark 17$ Deng J, Rodeck CH: Current applications of fetal cardiac imaging technology. Curr Opin Obstet Gynecol 2006;18:177-184.

18 Mirsky I, Parmley WW: Assessment of passive elastic stiffness for isolated heart muscle and the intact heart. Circ Res 1973;33:233243.

$\checkmark 19$ D’Hooge J, Heimdal A, Jamal F, Kukulski T, Bijnens B, Rademakers F, Hatle L, Suetens P, Sutherland GR: Regional strain and strain rate measurements by cardiac ultrasound: principles, implementation and limitations. Eur J Echocardiogr 2000;1:154-170.

$>20$ Kaluzynski K, Chen X, Emelianov SY, Skovoroda $\mathrm{AR}$, O'Donnell $\mathrm{M}$ : Strain rate imaging using two-dimensional speckle tracking. IEEE Trans Ultrason Ferroelectr Freq Control 2001;48:1111-1123.

-21 Galderisi M, Olibet M, Sidiropulos M, Innelli P, D’Errico A, de Divitiis O: Currently available technology for echocardiographic assessment of left ventricular function. Expert Rev Med Devices 2006;3:207-214.

-22 Burns AT, McDonald IG, Thomas JD, Macisaac A, Prior D: Doin' the twist: new tools for an old concept of myocardial function. Heart 2008;94:978-983.

23 Suhling M, Jansen C, Arigovindan M, Buser P, Marsch S, Unser M, Hunziker P: Multiscale motion mapping: a novel computer vision technique for quantitative, objective echocardiographic motion measurement independent of Doppler - first clinical description and validation. Circulation 2004;110: 3093-3099.

24 Marwick TH: Measurement of strain and strain rate by echocardiography: ready for prime time? J Am Coll Cardiol 2006;47: 1313-1327.
5 Zerhouni EA, Parish DM, Rogers WJ, Yang A, Shapiro EP: Human heart: tagging with MR imaging - a method for noninvasive assessment of myocardial motion. Radiology 1988;169:59-63.

26 Kim HK, Sohn DW, Lee SE, Choi SY, Park JS, Kim YJ, Oh BH, Park YB, Choi YS: Assessment of left ventricular rotation and torsion with two-dimensional speckle tracking echocardiography. J Am Soc Echocardiogr 2007;20:45-53.

27 Notomi Y, Lysyansky P, Setser RM, Shiota T, Popovic ZB, Martin-Miklovic MG, Weaver JA, Oryszak SJ, Greenberg NL, White RD, Thomas JD: Measurement of ventricular torsion by two-dimensional ultrasound speckle tracking imaging. J Am Coll Cardiol 2005; 45:2034-2041.

28 Takeuchi M, Nishikage T, Nakai H, Kokumai M, Otani S, Lang RM: The assessment of left ventricular twist in anterior wall myocardial infarction using two-dimensional speckle tracking imaging. J Am Soc Echocardiogr 2007;20:36-44.

29 Ashraf M, Li XK, Young MT, Jensen AJ, Pemberton J, Hui L, Lysyansky P, Friedman Z, Park B, Sahn DJ: Delineation of cardiac twist by a sonographically based 2-dimensional strain analysis method: an in vitro validation study. J Ultrasound Med 2006;25:1193-1198.

30 Zhang H, Li J, Liu L, Qian Y, Zhu T, Wei Z, Zhu Y, Zhang J, Zhou X: Quantitative assessment of myocardial acceleration in normal left ventricle with velocity vector imaging. Echocardiography 2008;7:699-705.

31 Roy S, Sankar V, Francis J, Tada H: Tissue tracking imaging for identifying the origin of idiopathic ventricular arrhythmias: a new role of cardiac ultrasound in electrophysiology. Indian Pacing Electrophysiol J 2005;5: 155-159.

32 Manovel A, Dawson D, Smith B, Nihoyannopoulos P: Assessment of left ventricular function by different speckle-tracking software. Eur J Echocardiogr 2010;11:417-421.

33 Amundsen BH, Helle-Valle T, Edvardsen T, Torp H, Crosby J, Lyseggen E, Stoylen A, Ihlen H, Lima JA, Smiseth OA, Slordahl SA: Noninvasive myocardial strain measurement by speckle tracking echocardiography: validation against sonomicrometry and tagged magnetic resonance imaging. J Am Coll Cardiol 2006;47:789-793.
34 Korinek J, Kjaergaard J, Sengupta PP, Yoshifuku S, McMahon EM, Cha SS, Khandheria BK, Belohlavek M: High spatial resolution speckle tracking improves accuracy of 2-dimensional strain measurements: an update on a new method in functional echocardiography. J Am Soc Echocardiogr 2007;20: 165-170.

35 Popovic ZB, Benejam C, Bian J, Mal N, Drinko J, Lee K, Forudi F, Reeg R, Greenberg NL, Thomas JD, Penn MS: Speckle tracking echocardiography correctly identifies segmental left ventricular dysfunction induced by scarring in a rat model of myocardial infarction. Am J Physiol Heart Circ Physiol 2007;292:H2809-H2816.

36 Taber LA, Sun H, Clark EB, Keller BB: Epicardial strains in embryonic chick ventricle at stages 16 through 24. Circ Res 1994;75: 896-903.

- 37 Becker M, Bilke E, Kuhl H, Katoh M, Kramann R, Franke A, Bucker A, Hanrath P, Hoffmann R: Analysis of myocardial deformation based on pixel tracking in two dimensional echocardiographic images enables quantitative assessment of regional left ventricular function. Heart 2006;92:11021108.

38 Cho GY, Chan J, Leano R, Strudwick M, Marwick TH: Comparison of two-dimensional speckle and tissue velocity based strain and validation with harmonic phase magnetic resonance imaging. Am J Cardiol 2006;97:1661-1666.

-39 Nesbitt GC, Mankad S, Oh JK: Strain imaging in echocardiography: methods and clinical applications. Int J Cardiovasc Imaging 2009;25(suppl 1):9-22.

40 D’Hooge J, Bijnens B, Jamal F, Pislaru C, Pislaru S, Thoen J, Suetens P, Van de Werf F, Angermann C, Rademakers FE, Herregods MC, Sutherland GR: High frame rate myocardial integrated backscatter: does this change our understanding of this acoustic parameter? Eur J Echocardiogr 2000;1:3241. 